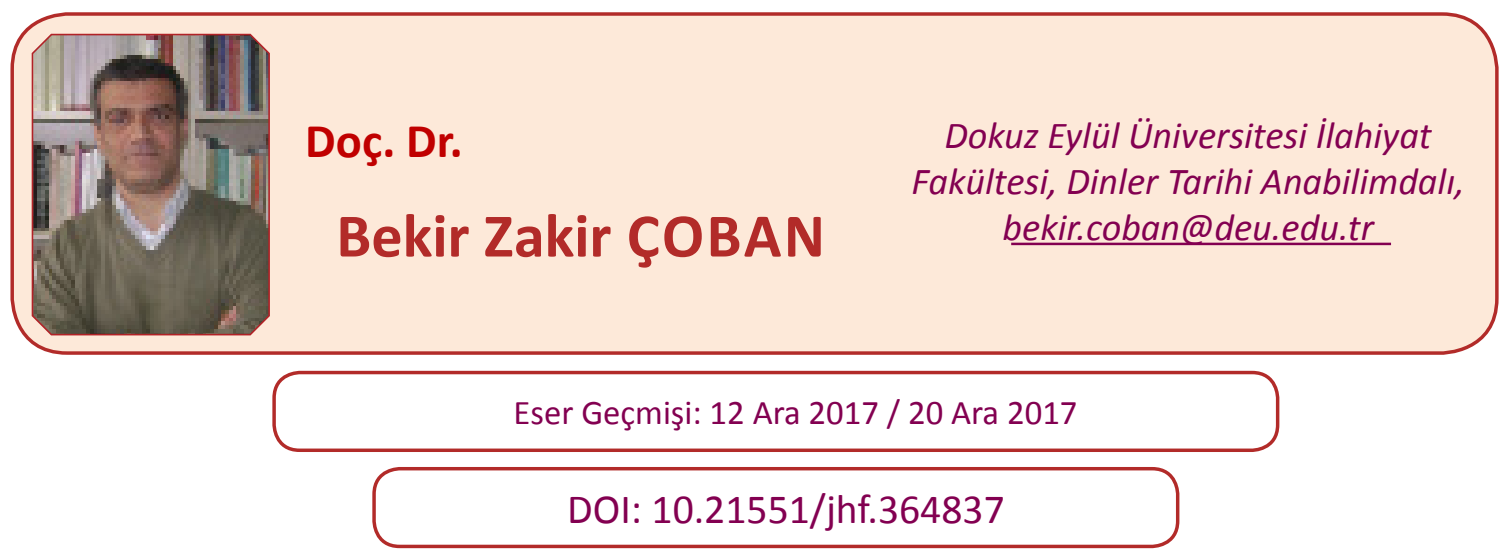

\title{
Angelo Giuseppe Roncalli’nin İstanbul Günleri
}

\author{
Angelo Giuseppe Roncalli's Istanbul Days
}

\section{ÖZET}

Zaman zaman "Türk papa" olarak adlandırılan Angelo Giuseppe Roncalli 1958-1963 yılları arasında papalık makamında bulunmuştur. Türkiye-Vatikan ilişkileri açısından önemli bir kişiliktir. Zira papa olmadan önce, 1935'ten 1944'e kadar Papalık Temsilcisi olarak İstanbul'da görev yapmıştır. Katolik ibadetlerinde ilk kez Türkçe kullanılması, Türk siyasetçi ve bürokratları ile kurduğu ilişkiler, Avrupa'dan Nazilerden kaçan birçok yahudiye yardım etmesi onun Türkiye'deki günlerindeki önemli faaliyetleri arasındadır. Roncalli'nin Doğu tecrübesi onun papalık dönemine de etkide bulunmuş bir arka planı oluşturmaktadır. Elinizdeki çalışma daha çok kendine ait metinler ışığında Roncalli'nin Ístanbul günlerini mercek altına almak amacındadır.

Anahtar Kelimeler: Angelo Giuseppe Roncalli, Papa XXIII. John, Papalı,, Vatikan

\section{ABSTRACT}

Angelo Giuseppe Roncalli, sometimes called "Turkish pope", was seat on the papal chair between 1958-1963. He is an important person in terms of Turkey-Vatican relations. Because, before he became pope, he served in Istanbul as a Papal Representative from 1935 to 1944. First use of Turkish in the Catholic rituals; his relations with Turkish politicians and bureaucrats; helping many Jews escaping from Nazis in Europe are his important activities during his days in Turkey. The Eastern experience of Roncalli has also established an influential background in his papacy. This work aims examining Roncalli's Istanbul days in the light of his own texts.

Keywords:Angelo Giuseppe Roncalli, Pope John XXIII, Papacy, Vatican 


\section{Angelo Giuseppe Roncalli Kimdir?}

1958 yılında papa seçilerek XXIII. John ismini alan Angelo Giuseppe Roncalli 25 Kasım 1881'de İtalya'nın Bergamo şehri yakınlarındaki Sotto il Monte kasabasında doğmuştur. Kalabalık ailesi çiftçilikle geçinmektedir. Dindar bir Katolik olan amcasının teşvikiyle Bergamo ve Roma'da kilise okullarına devam etmiş ve 1904'de rahip olmuştur. RoncalliI. Dünya Savașı'na ordu papazı olarak katılmıştır. 1920'de dönemin papası XV. Benedict tarafından Papalığın misyonerlikle ilgili önemli kuruluşlarından biri olan Propaganda Fide'de görevlendirilmiştir. 1925'te piskoposluğa yükselmiş ve Bulgaristan'a Papalık Temsilcisi (ApostolicDelegate) olarak atanmıştır. 1935'e kadar burada görev yapan Roncalli 1935'ten 1944'e kadar ise Papalığın hem Yunanistan hem TürkiyenezdindekiPapalıktemsilcisi olarak çalışmıştır. Fakat o dönemde Türkiye ile Vatikan arasında henüz diplomatik bir ilişki bulunmadığından Roncalli'nin temsilciliği “gayrı resmî”dir. Türkiye'deki görevinin ardından 1944'te Fransa'ya Papalık Elçisi (Nuncio) olarak atanan Roncalli aynı zamanda UNESCO'da Vatikan'ın ilk daimî temsilcilisidir. 1953 yılında kardinalliğe yükselen Roncalli, Papa XII. Pius'un ölümü üzerine papa seçilmiş ve papalık ismi olarak "XXIII. John” adını adını almıştır.

Roncalli Katolik Kilisesinde önemli değişimlere imza atmış bir kişiliktir. HansKüng gibi teologlar bu bakımdan onu,papalığın kurumsallaşma sürecinde ciddi bir role sahip olan Papa Büyük Gregory(590-604 yılları arasında papalık yapmıștır)'ye benzetmektedir.'XXIII. John, 1471-1484 yılları arasında görev yapan IV. Sixtus tarafından kardinallerin sayısına getirilen sınırlamayı (Sixtus bu sayıyı 70 ile sınırlandırmıştı) kaldırmıștır ve Kilisedeki kardinal sayısı onun zamanında tarihteki en yüksek rakama (87) ulaşmıştır. Papa XXIII. John ayrıca Kilise Yasası'nı revize etmiş ve Kilisede ekümenizm ve diğer dinlerle ilişkiler gibi konularda müstakil kurumlar oluşturmuştur. Tüm bunlarla birlikte Roncalli'nin Katolik Kilisesinin XX. Yüzyılına damgasını vuran en önemli icraatı II. Vatikan Konsili'ni toplamasıdır. Papa XXIII. John konsil devam ederken 3 Haziran 1963'te ölmüştür. Papa II. John Paul tarafından 2000 yılında "ermiş" (blessed); Nisan 2014'te şu anki papa I. Françis tarafından “aziz" ilan edilmiştir. ${ }^{2}$

İtalya'da halen papa buono (iyi papa) olarak anılan Angelo GiuseppeRoncalliarkasında binlerce sayfalık malzeme bırakmıştır. Günlükleri ve mektupları bunlar arasında en önemli olanlarıdır. Venedik Patrikliğinden itibaren ölümüne kadar yanından ayırmadığı sekreteri Mgr. Loris F. Capovilla bu günlükleri ve mektupları papanın ölümünü takip eden yıllar içinde yayınlamıştır. Ayrıca görev yaptığı yerlerde ve Bologna'da adına kurulan enstitüdeki (Fondazioneper le ScienzeReligioseGiovanni XXIII) arşivlerde de önemli miktarda belge mevcuttur. Günlükleri İtalyanca dışında henüz yayınlanmamış olsa da mektupları, çeşitli konuşmaları ve vaazları birçok batı diline çevrilmiştir. Ayrıca Roncalli ile ilgili çok sayıda biyografi mevcuttur. Neredeyse tamamı Katolik yazarlar tarafından kaleme alınan bu eserler doğal olarak duygusal bir tona sahiptir. Onun hakkında yazılanlara bakıldığında hem lehinde hem aleyhinde pek çok efsane olduğu görülür. ${ }^{3}$

1 Bkz. HansKüng, TheChurch (Image Books,: New York, 1976), 599.

2 Vatikan resmî sitesindeki biyografi için bkz. http://w2.vatican.va/content/john-xxiii/en/biography/documents/ hf_j-xxiii_bio_16071997_biography.html

3 Bologna'daki enstitü tarafından 10 cilt halinde yayınlanan günlükler içerisinde en hacimli yeri İstanbul yılları tutar. İki büyük cilt halindeki günlükleri 2000 sayfa civarındadır. Bunun dışında Roncalli'nin ruhsal günlüğü olarak görülen “ruhun yolculuğu” İtalyanca ve İngilizce olarak yayınlanmıştır. Mektupları da Roncalli’ye ait farklı dillerde yayınlanan metinlerdendir. Günlükler ve kendine ait diğer metinler için bkz. Angelo GiuseppeRoncalli, 


\section{Türkiye'ye Gelişi ve İlk Günleri}

Roncalli Türkiye'ye ilk kez görevi dolayısıyla gelmemiştir. Bulgaristan'da iken çeşitli defalar İstanbul'u ziyaret etmiștir. Hatta Bulgaristan'daki görevinin son yılında yaz tatilini neredeyse tamamen İstanbul'da geçirmiştir. Roncalli üzerine yazılan bazı biyografilerde Atatürk ve diğer Türk yöneticilerin adeta Katoliklere yönelik özel bir bastırma ve sindirme gayreti içinde olduklarını iddia edilir. ${ }^{4}$ Roncalli de Bulgaristan dönemine ait günlüklerinde bu anlama gelebilecek bazı ifadeler kullanır. ${ }^{5}$ Fakat bu durum muhtemelen onun Türkiye'yi yeterince tanımamasından kaynaklanmaktadır. Zira İstanbul'a gelip bir süre yaşadıktan sonra bu düşüncelerinin değiştiği görülür.

Angelo RoncalliPapalık Türkiye ve Yunanistan temsilcisi olarak görevlendirildiğini Roma'da, 17 Kasım 1934'te öğrenmiştir. ${ }^{6}$ Hiyerarşi gereği, daha sonra XII. Pius adıyla papalık makamınaoturacakolanDevletSekreteriEugenioPacelli'yebağlıolarakçalıșacaktır. Monsenyör Roncalli 5 Ocak 1935 Cumartesi günü Haydarpaşa Garı'na iner. Kendisini, İstanbul'da sekterliğini yapacak olan Milanolu Angelo Dell'Acqua karşılar. ${ }^{8}$ İlk iş olarak polis karakoluna gidip Türkiye'ye gelişi ile ilgili bilgi verir. ${ }^{9}$ Gelir gelmez beklenmedik biçimde zamanın İstanbul Valisi Muhiddin Üstündağ tarafından davet edilir. Üstündağ, Roncalli'nin Türkiye'de tanıștığı ilk devlet yetkilisidir. Aralarında sıcak bir sohbet geçer. ${ }^{10}$ İkametgahı Şişli'deki Ölçek Sokak'tır.

Giovanni XXIII, IlGiornaledell'anima, Soliloqui, note e dairi spirituali (Edizionecritica e annotazione a cura diAlbertoMelloni, Istitutoper le ScienzeReligiosedi Bologna: Bologna, 2003); La miavita in Oriente, Agende del delegatoapostolico 1: 1935-1939 (Edizionecritica e annotazione a cura diValeriaMartano, Istitutoper le ScienzeReligiosedi Bologna: Bologna, 2006); La miavita in Oriente, Agende del delegatoapostolico 2: 1940-1944 (Edizionecritica e annotazione a cura diValeriaMartano, Istitutoper le ScienzeReligiosedi Bologna: Bologna, 2008); Pope John XXIII, Lettersto His Family, trans. byDorothy White (McGraw-HillBookCompany: New York, 1970); Giovanni XXIII, Lettereaifamiliari 1901-1962, a cura diLorisFrancescoCapovilla, vol. I-II, EdizionidiStoria e Letteratura: Roma, 1968). Roncalli’nin Türkiye dönemi ile ilgili en ayrıntılı çalışma ise AlbertoMelloni’ye aittir. Melloni bu çalışmasında İtalya ve Türkiye'deki arşivleri de kullanmıştır. Bkz. AlbertoMelloni, FraIstanbul, Atene e la guerra: La missionedi A. G. Roncalli (1935-1944) (Marietti: Genova, 1992). Roncalli'nin Türkiye y1llar1 için ayrica bkz. Leone Algisi, John thetwenty-third, trans. by Peter Ryde (NewmannPress: London, 1966) 93133; StefanoTrinchese, "Roncallidiplomatico in Grecia e in Turchia", Pio XII (EditoriLaterza: Bari, 1984), 231264; RobertoMorozzoDellaRocca, "Roncallidiplomatico in turchia e greca", Christianesimonellastoria (VIII/2, giugnio 1987), 33-72. Türkçede Roncalli ile ilgili yayınlanmış yegane eser Rinaldo Marmara’ya aittir. Marmara bu eserinde Roncalli'nin Türk dostluğunu ön plana çıkarmaktadır ve kendisinin de belirttiği üzere "bu kitabın yazarı Mgr. Roncalli'nin görüşüne sadık kalarak metinlerin araştırılması sırasında 'ayıran ve zıtlık oluşturandan daha çok birleştirici’ nitelikteki metinleri seçmeye özen göstermiştir”. Rinaldo Marmara, Türk Dostu Papa XIII. Jean, çev. Dominik Pamir (İstanbul: 2000), 16.

4 Peter Hebblethwaite, John XXIII, Pope of theCouncil (GeoffryChapman: London, 1984), 140.

5 Bkz. XV anniversariodellamortedi papa Giovanni, 1963 -3 giugno- 1978 (EdizionidiStoria e Letteratura: Roma, 1978), 72.

6 Angelo GiuseppeRoncalli, Giovanni XXIII, Tener da conto, AgendediBulgaira 1925-1934 (Edizionecritica e annotazione a cura diMassimoFaggioli, Istitutoper le ScienzeReligiosedi Bologna: Bologna, 2008), 260.

7 Bkz. Capovilla,TheHeartandMind of John XXIII, trans. byPatrickRiley, HawthornBooks: New York, 1964), 155.

8 Roncalli ve Dell'Acqua arasındaki dostluk İstanbul'la sınırlı kalmayacak, ileriki yıllarda da devam edecektir. Konuyla ilgili bir çalışma için bkz. MauroLanfranchi (ed.), AngeloGiuseppeRoncalli, Angelo Dell'Acqua, Documentidi un' amicizia (1926-1963) (NED: Milano, 2002).

9 Roncalli biyografları maalesef Türkiye şartlarını çoğunlukla abartmaktadır. Mesela Hebblethwaite, Roncalli'nin her gittiği yerde bir şüpheli gibi izlendiğinden bahseder (Hebblethwaite, 143). Oysa Roncalli'nin kendi metinlerinde böyle bir ifade ya da ima geçmez. Ayrıca yazar cumhuriyetin kuruluşunu "mollalara karşı Jöntürklerin isyanının bir sonucu" gibi oldukça basit bir formülle ifade eder (bkzHebblethwaite,, 144) ki bu da isabetsiz bir yorumdur. 
Bu sokağa yıllar sonra kendisinin ismi verilecektir. Türkiye'deki zamanının çoğunluğunu Ölçek Sokak'taki bu mekanda geçirecektir. Kaldığı binanın ve buradaki şapelin durumu kötüdür. Zaman içerisinde şapeli elden geçirip, kütüphane ve arşivi tekrar düzenler.Ortodoks Kilisesi, Yunanistan, Türkiye, II. Dünya Savaşı, Türkiye'deki Katolikler.. Bunlar arasında Roncalli'yi İstanbul'da zor bir görev beklemektedir. Üstelik selefi, yani bir önceki Papalık temsilcisi Margotti'den hiç de iyi bir miras devralmamıştır. ${ }^{11}$ Zira Margotti devlet erkanı ile de Katolik cemaati ile de pek geçinememiş biridir. Fakat Roncalli hoşgörüsü, sabrı ve iyi insani ilişkileri sayesinde hem Türk yetkililerle hem de yabancı misyon görevlileriyle iyi ilişkiler kurmuş; Türkiye'de yaşayan farklı milliyetlere mensup Katolikler arasında da bir ahenk sağlamaya çalışmiştır.

İstanbul ve çevresinde o dönem 35.000 civarında Katolik yaşamaktadır. Bunlar arasında Alman, İtalyan, Avusturyalı ve Fransız kökenliler olduğu gibi; Ermeni, Maruni, Melkit ve Rum kökenli uniatlar da vardır.Roncalli aynı zamanda Yunanistan'dan da sorumludur. Yunanistan'daki Katolik nüfus o yıllarda 50.000 civarındadır ve buradaki Katolikler Ortodoks Kilisesi'nin baskısını her alanda hissetmektedirler. Ayrıca siyasi partiler arasındaki çekişmeler, İngilizlerin müdahaleleri gibi etkenler bu ülkedeki durumu daha da zorlaștırmaktadır. Roncalli büyük oranda bu şartlardan dolayı Türkiye'de gösterdiği etki ve başarıyı Yunanistan'da gösteremez. Yunanistan'da Katolikler için barışçıl ve uyumlu bir ortam yaratmak amacıyla var gücüyle çalıșır, hatta sırf buradaki meselelerden ötürü birkaç kez Roma'ya gitmek mecburiyetinde kalır. Fakat özellikle II. Dünya Savaşının başlamasından sonra Roncalli'nin Yunanistan'la irtibatı önemli ölçüde kesilmiştir. ${ }^{12}$

O dönem Türkiye'sinin şartlarının da Roncalli için kolay olduğu söylenemez tabi ki. Her şeyden önce Roncalli'nin Türkiye'deki görevi "gayrı resmi"dir. Zira o zamanlar Türkiye ile Vatikan arasında diplomatik bir ilişki yoktur. İki ülkenin birbirini tanıması ve diplomatik ilişki kurması Roncalli papa olunca gerçekleşecektir. Bunun dışında Kıyafet Kanunu ve Tevhid-i Tedrisat gibi düzenlemeler Müslümanlar yanında Türkiye Katoliklerinin, dolayısıyla Roncalli'nin de doğrudan etkilendiği gelișmelerdir. Dini kisvelerin giyilmesini yasaklayan düzenleme Roncalli'nin Türkiye’ye gelir gelmez karşılaştığı ilk sorun olur. ${ }^{13}$ Günlüklerine bu konuda "herkes için büyük bir sınav. Umarım bununla kalır" diye yazmıştır. ${ }^{14}$ Fakat bunu büyük bir mesele olarak görmez. Rahipliğin kıyafetle olmadığını ifade eder, hatta sivil kıyafetlerle resimler çektirir. Diğer önemli bir sorun ise Hıristiyan okullarıdır. Tevhid-i Tedrisat Kanunu'nun kabulünden sonra misyoner ve azınlık okulları Milli Eğitim Bakanlığı'nın

11 Bkz. Melloni, FraIstanbul, 37-48; Marmara, 34-36. Roncalli'den sonra da Papalık temsilcisi olarak birçok isim görev yapmıştır. Bunlardan biri de Galatasaray Lisesi'nin meşhur hocalarından Pierre Dubois’tir. Aslında Dubois ve Roncalli Türkiye'de aynı zamanda bulunmuşlardır. Fakat Roncalli günlüklerinde (yayınlanan haliyle) ondan hiç söz etmez. Dubois'le ilgili bkz. Niyazi Öktem, Kemal Suman, Turhan Ilgaz, Galatasaraylı Monsenyör Pierre Dubois'nin Anı ve Görüşleri (Zaman Kitap: İstanbul, 2001).

12 Bkz. StefanoTrinchese, "Roncallidiplomatico in Grecia e in Turchia", Pio XII (EditoriLaterza: Bari, 1984), 231-264; RobertoMorozzoDellaRocca, "Roncallidiplomatico in Turchia e greca", Christianesimonellastoria, VIII/2, giugnio 1987, 33-72.

13 Hebblethwaite, Atatürk'ün Hıristiyan ruhbanların kıyafetlerini yasakladığını söyler. Oysa bu yasak Hıristiyanlara has değildir, Müslümanları da kapsamaktadır. Yakın zamanda bazı gazete ve kitaplarda Atatürk'ün kılık kıyafet kanunu gereğince din adamlarının dini kıyafet giyememeleriyle ilgili şöyle bir iddia dile getirilmektedir: Atatürk'ün özel terzisine emrederek Roncalli için sivil kıyafetler hazırlattığ 1 şeklinde bir iddia dile getirilmektedir (örnek olarak bkz. İbrahim Sarı, Büyük Deha Atatürk (İstanbul, 2017), 108). Fakat ne Roncalli'nin kendi metinlerinde ne de herhangi bir başka kaynakta buna dair bir işaret veya iz mevcut değildir.

14 Capovilla, XV anniversario, 78. 
denetim ve gözetimine girmiş; dini ve siyasi amaçlı eğitim yasaklanmış; ders programlarına tarih, coğrafya, yurttaşlık bilgisi, Türkçe dersleri eklenmiştir. Kanun 1924'te çıkmış olsa da etkileri hala devam etmektedir. Azınlık okullarında okutulan kitaplardan aziz resimleri çıkarılır; okul binalarındaki haçların indirilmesi istenir. Dini sembollerin yalnızca okul kiliselerinde bulundurulmasına izin verilir. Din esaslarına dayalı eğitim ve din propagandası yapma yasaklarına uymayan yabancı okullar ise derhal kapatılmaktadır. Bunlar arasında Merzifon ve Kayseri'deki Amerikan okulları, İzmir'deki Fransız okulu ve diğer bazı Katolik okulları da vardır. Vatikan, Roncalli'yi direnmesi için zorlar, fakat "gayrı resmi" temsilcinin yapabilecek fazla bir şeyi yoktur. Özetle RoncalliTürkiye'de, bir yandan Ortodoks bir yandan İslam Dünyasının, bir diğer taraftan ise genç Türkiye Cumhuriyetinin, o zamanki zor şartları içerisinde bir görev süreci geçirmiştir.

\section{Kilise Ayinlerinde Türkçenin Kullanılmasına Katkısı}

Roncalli Roma'dan ve İtalya'dan uzak olmanın bazı dezavantajlarına sahiptir ama İstanbul'da olmak "dışarı" tecrübesi yanında bir de özgür düşünme açısından bir avantajdır. Şubat 1938'de yazdığı bir mektupta İstanbul'da olmaktan mutlu olduğunu çünkü burada kendi tarzında rahatça çalışabildiğini yazmaktadır. ${ }^{15}$

Roncalli Türkçeye oldukça ilgili duymuş ve Türkçe öğrenmeye gayret etmiştir. ${ }^{16} 1936$ yılında onun teşviki ile Türkiye'deki Katolik kiliselerindeki ayinlere Türkçe ifadeler girmeye başlar. Bunu ilk kez kendisi yapmıştır. "Tanrı mübarek olsun" ayinde telaffuz ettiği ilk Türkçe cümledir. ${ }^{17} \mathrm{Bu}$ ifadeyi Türkiye'deki ayinlerinde daha sonra sürekli kullanır. ${ }^{18}$ Tıpkı kıyafet konusunda olduğu gibi ayin için de kalıplardan ziyade içeriğin önemli olduğu düşüncesindedir. Fakat anlaşılan Roncalli'nin bu bakış açısına Katolik cemaati pek hazır değildir. Yukarıdaki Türkçe cümleyi telaffuz ettiğinde bazıları kiliseyi terk eder. Fakat o memnundur. Takip eden günlerde pek çok Avrupalı sefirin masasında Türkçe Kutsal Kitap gördügünü söyler. ${ }^{19}$ İstanbul'da ikamet etse de, polis merkezinden izin alarak sıkça Ankara'ya gitmektedir. Türk yetkililer ve Ankara'daki yabancı diplomatlar arasında gittikçe tanınan ve sevilen bir isim haline gelir. İngiltere, Amerika, Almanya, Belçika, Polonya ve İtalya büyükelçileriyle iletişim kurar. Hatta bazı biyografları onun Ankara'daki diplomasisinde İncil'den ziyade Machiavelli'yi referans aldığı yorumunu yapmaktadır. ${ }^{20}$

Roncalli, Mayıs ayında Yalova, Gemlik, Bursa, İznik ve Mudanya'yı ziyaret eder. ${ }^{21} 1938$ Ocak ve Mart aylarında İzmir'e gider. Burada İzmir Başpiskoposu Giuseppe Descuffi ile görüşür ve Bergama'yı gezer. ${ }^{22} 1939$ Mayısında Fener Rum Patriği I Benjamin'i ziyaret eder. ${ }^{23}$ Aynı ay Beyrut'ta Kardinal Tisserant'ın düzenlemiş olduğu Evharistiya Kongresi'ne katılır. Beyrut'tan

15 Angelina e GuiseppeAlberigo, Giovanni XXIII, (EditriceQueriniana: Brescia, 1978), 448.

16 Roncalli, Journal, 228.

17 Bkz. Capovilla, Heart, 156; Melloni, FraIstanbul, 104, 105.

18 Roncalli, OrienteI, 155.

19 MeriolTrevor, Pope John, Blessed John XXIII (MPG Books: London, 2000), 169.

20 Hebblethwaite, 150.

21 Roncalli, Oriente I, 332-335.

22 Roncalli, Oriente I, 458, 459, 481.

23 Roncalli, Oriente I, 680. 
Filistin ve Suriye'ye geçerek bu bölgede Kudüs, Hayfa, Yafa, Palmira, Humus ve Halep'i görür. ${ }^{24}$ Eylül ayını ise Roma ve memleketi Sotto il Monte'de geçirir. ${ }^{25}$ Ekim ayında Roncalli Akdeniz bölgesindedir, Türkiye'de ramazan ayıdır. Adana, Tarsus, İskenderun, Antakya ve Mersin'i ziyaret eder. Konya, Afyon ve İzmir üzerinden İstanbul'a döner. ${ }^{26}$

Roncalli İstanbul'a hayran kalır. Şehirde adeta bir müzede gibi hisseder kendisini. "Büyük Sinan" diye bahsettiği Mimar Sinan'ın eserlerinden övgüyle söz eder. ${ }^{27}$ İlk Hıristiyan konsillerin gerçekleştiği bu topraklar aynı zamanda onun teolojik dünyası açısından da farklı bir tecrübedir. Bazı biyograflarına göre "burada Roma dar görüșlülüğünden kurtulmuștur". ${ }^{28}$ Bunun, onun pastoral anlayışı ve konsilciliğinde önemli bir etkisi olduğu düşünülebilir. Fakat İstanbul ve Türkiye ile sadece Hıristiyan mirası bakımından ilgili değildir. Osmanlı sultanlarının hayatları ve eserlerinden son derece etkilenmiştir. ${ }^{29}$ II. Abdülhamid gibi son dönem sultanları ile ilgili bazı hatıraları o günleri bizzat yaşamış kişilerden dinlemiştir. ${ }^{30} \mathrm{Hatta}$ hanedan üyelerinin yurtdışına çıkarıldıktan sonra düştükleri zor durumlardan haberdardır. ${ }^{31}$ Sultan Abdülmecid'in sadrazamlarından Kıbrıslı Mehmed Emin Paşa'nın torunu Refika Edhem Dirvana ile tanışmış, sohbet etmiştir. Refika Edhem'den “çok iyi eğitimli bir hanımefendi" diye bahseder. $^{32}$

Roncalli Osmanlı'dan Cumhuriyet'e geçiş serüveni ve dönemin siyasi gelişmeleri ile de alakadardır. Yakın dönem Türkiye tarihi ile ilgili konferanslara katılır. Francesco Psalty’nin Namık Kemal üzerine İstanbul'da verdiği konferans bunlardan biridir. ${ }^{33}$ Roncalli Atatürk'le hiç karşılaşmamıştır. Fakat onun "yurtta barış dünyada barış" sözünü çok anlamlı bulur. ${ }^{34}$ Hatta papa olduktan sonraki en önemli genelgelerinden birinin Pacem in Terris (Dünyada Barış) adını taşıması bu açıdan anlamlıdır. Türklerin Atatürk'ün yolunda ilerlediğini söyler. ${ }^{35}$ Fakat Sarayburnu'ndaki Atatürk heykeline (Türkiye'deki ilk Atatürk anıtıdır) bakarak "ulusunu seyrediyor, acaba ne görüyor?" diye sormadan edemez. ${ }^{36}$ Sonra boğaza bakarak "Mehmet [Fatih]'in tahtına İsa'nın oturacağı günler"i hayal eder. ${ }^{37}$ Atatürk'ten sonra İsmet İnönü Cumhurbaşkanı seçildiğinde ise “daha iyi mi olacak daha kötü mü?” diye sorar ve "Tanrı́nın elindeki bir sır" şeklinde cevap verir. ${ }^{38}$

\footnotetext{
24 Roncalli, Oriente I, 682-688.

25 Roncalli, Oriente I, 722-729; Melloni, FraIstanbul, 171-176.

26 Roncalli, Oriente I, 736-741.

27 Roncalli, Oriente I, 519.

28 Hebblethwaite, 172.

29 Bkz. Roncalli, Oriente I, 334.

30 Roncalli, Oriente II, 199.

31 Roncalli, Oriente I, 670.

32 Roncalli, Oriente II, 635.

33 Roncalli, Oriente II, 395. Günlükleri yayına hazırlayanlar Namık Kemal'i "mason bir milliyetçi Türk” diye tanımlar. Bkz. aynı sayfa 130 numaralı dipnot.

34 Roncalli, Oriente II, 85.

35 Roncalli, Oriente II, 522.

36 Roncalli, Oriente I, 296.

37 Roncalli, Oriente I, 296.

38 Roncalli, Oriente I, 587; Melloni, FraIstanbul, 176-182.
} 


\section{Bir Kilise Adamı Olarak II. Dünya Savaşında Roncalli}

1935 yılının Ağustos sonunda birkaç günlüğüne Yunanistan’a geçer. Burada birkaç şehri ziyareteder. Ekim ayında, o yılki tatilinde, Roma'ya giderve arkadaşlarıyla buluşur. Kendisinden sonra VI. Paul adıyla papa olacak olan Montini de görüștüğü arkadaşları arasındadır. ${ }^{39} 0$ sıralar Mussolini'nin askerleri Abissina'yı işgal etmiştir. Fakat Vatikan ve Vatikan'ın resmi yayın organı L'OsservatoreRomano sanki hiçbir şey olmamış gibi davranmakta, işgal ve burada yapılan katliam hakkında tek kelime etmemektedir. Roncalli Kilisenin bu sindirilmişliği ile ilgili açıktan hiçbir şey söyleyemez. Fakat kendisi aynı fikirde değildir. Mektuplarında işgalin iyi bir şey olmadığını, nihayetinde bunun bir savaş olduğunu belirtir ve kısa sürede sona ermesi için dua eder. ${ }^{40}$ Aslında İtalya'nın saldırısı o bölgedeki Hıristiyanlara dahi zarar verecek niteliktedir. Ama işgalciler, tıpkı günümüzde savaşla demokrasi götürme yanlıları gibi, "barbarlara medeniyet götürme" iddiasındadırlar. ${ }^{41}$

Selefi Margotti Yunanistan konusunda da Roncalli'ye iyi bir miras bırakmamıştır.Özellikle Ortodoks Rumlar yeni Papalık temsilcisine karşı hayli şüphecidirler. Roncalli Latinlere karşı olan bu antipatinin Haçlı Seferlerine kadar dayanan bir geçmişi olduğunun farkındadır. ${ }^{42}$ Tıpkı Türkler gibi Rumlar da Latinleri "Frenkler" olarak adlandırmakta, yani yabancı ve düșman bir unsur olarakgörmektedirler. ${ }^{43}$ Üstelik Mussolini'nin saldırgan Akdeniz politikası Yunanistan'ın İtalya ile olan ilişkilerini hayli gergin hale getirmiştir. Zira 1923'te İtalyanların Korfu adasını işgali ve bombardımanda pek çok Rum'un öldürülmesi Yunanlıların hafızasında hala tazedir. General Metaxas aşırı milliyetçi hükümetin başındadır ve Vatikan’ı Mussolini'nin destekçisi olarak görmektedir. Katolikler ve Uniatların kiliselerini tamir etmelerine izin verilmemekte, Ortodoks Kilisesi dışındaki kiliselerde kıyılan nikahlar geçersiz sayılmaktadır. Bir yandan siyasi karışıklıklar diğer yandan Almanya ve İtalya'nın dış baskısı Roncalli'nin işini daha da zorlaștırmıştır. Nasıl bir temsilci rolünde olacağı bir yana, hukuki statüsü dahi belli değildir ve hiçbir zaman da netleşmemiştir. Mayıs 1936'da Yunanistan Kralı II. George ile bir araya gelmesi de dostane, fakat problemleri çözme açısından sonuçsuz bir görüşme olarak kalır. Eli kolu bağlı biçimde “Roma'dan gelecek talimatları” beklemektedir. Günlüklerinde Türkiye ile kıyaslandığında Yunanistan'la ilgili sorunların çok daha fazla olduğunu ifade etmektedir. ${ }^{44}$

1937 yılına gelindiğinde Papa XI. Pius'un sağlı̆̆ı pek iyi gözükmemektedir. Fakat Papa Mart ayında iki genelge yayınlar: Mit Brennender Sorge (14 Mart 1937) ve Divini Redemptoris (19 Mart 1937). Bu iki genelge Almanya'da Katolik Kilisesinin durumu ve komünizm tehlikesi hakkındadır. Yani Papa Nazizm ve Komünizmi hedef almıștır ama Mussolini hakkında konuşamamaktadır. O yıllarda Mussolini ile Hitler arasında Kiliseyi korkutan bir yakınlaşma söz konusudur. Mayıs 1938'de Roma sokakları gamalı haçlarla donatılır. Zira Hitler ziyarete gelmiștir. L'Osservatore Romano ziyareti görmezden gelir; Vatikan'a bağlı tüm müzeler ziyaret boyunca kapalı tutulur. Hitler'in gelişi Kiliseyi oldukça rahatsız etmiş ve Mussolini

\footnotetext{
39 Roncalli, Lettersto His Family, 269, 270.

40 Roncalli, Lettersto His Family, 271, 272.

41 Hebblethwaite, 148.

42 Bkz. Roncalli, XV anniversario, s. 82.

43 Hebblethwaite, 150. Roncalli’nin Yunanistan'daki faaliyetleri ve yaşadığı sorunlar hakkında ayrıca bkz. Algisi, , 135-157.

44 Roncalli, Lettersto His Family, 305.
} 
hükümeti ile arasını daha da açmıştır. Ancak Vatikan'ın açıktan bir muhalefette bulunma gücü yoktur. ${ }^{45}$ Roncalli ise günlüklerinde Hitler'den “Tanrı'nın ve Kilise'nin düșmanı” diye bahseder. ${ }^{46}$

Devlet Sekreteri Eugenio Pacelli kısa bir süre sonra yapılacak seçimden papa olarak çıkacak isimdir. İtalya'nın Arnavutluğu işgali ${ }^{47}$ ve II. Dünya savaşının hızla yaklaştığı bir ortamda yeni papayı zorlu günler beklemektedir. Roncalli seçimden önce yeni papanın hayatını değiştirmemesini umduğunu ve o anki durumundan memnun olduğunu yazmıştır. ${ }^{48}$ Pacelli seçilip XII. Pius adını alarak papalık tahtına oturduğunda da, Tanrı'nın eliyle gerçekleşen bir seçim olduğunu belirtir ve memnuniyetini ifade eder. ${ }^{49}$ Mart ayında yeni Papa için düzenlenen ayine Fener Rum Patriği I. Benjamin de katılır. Ayin bitiminde Roncalli Patriğe Fener'e kadar eşlik eder. ${ }^{50}$ Savaşın patlak verdiği günlerde ise İtalya'dadır. Bu ziyaretinde Papa ile de görüşür. Fakat İtalya henüz savaşa dahilolmamıștır. Hitler'in Polonya'yı işgali ile başlayan savaşta, İstanbul'a dönüşünde kendisini Polonya'dan kaçanlara yardım organizasyonu yaparken bulur. 1940 yılına girildiğinde Vatikan'dan Yunanistan'la daha çok ilgilenmesi yönünde bir emir alır. Ocak ve Mayıs ayları arasında birçok defa Yunanistan'a giderek orada çalıșır. Fakat durum Roncalli'nin düzeltebileceği boyutta değildir. Siyasi konjonktür açısından da İtalya'nın Yunanistan'ın kapısına dayandığı bir ortamda Roncalli'nin işi oldukça zordur. Fakat savaşın ortasında Türkiye gibi tarafsız bir ülkede bulunması onun için avantajlı olmuștur. ${ }^{51}$

Savaşın merkezi denebilecek Almanya'nın o dönem Türkiye büyükelçisi Franz Von Papen'dir. Papen 1939 yılında Türkiye'deki görevine bașlar ve Roncalli'nin sürekli görüştüğü isimlerden biri olur. Bir yll sonra Papen ismi Vatikan büyükelçiliği için önerilir. Fakat Alman Başpiskoposu Von Preysing'den görüşünü sorup olumsuz cevap alan Papa XII. Pius buna izin vermez,Von Papen Türkiye'de kalır. ${ }^{52} \mathrm{Bu}$ arada Almanya 1940'ın Mayıs ayında Hollanda, Luxenburg ve Belçika'yı işgal eder. Haziran ayına gelindiğinde Paris Almanların eline geçmiştir ve artık İtalya'da savaşın içindedir. Roncalli'nin tarafsızlığı nedeniyle övdüğü Mussolini sözünü tutmamıştır. Palazzo Venezia'nın balkonundan yaptığı konuşmada "macera başlıyor" der Mussolini, "Tanrı İtalya'nın yardımcısı olsun”. ${ }^{53}$

45 Bkz. Hebblethwaite, 155.

46 Roncalli, Oriente I, 744.

47 RoncalliArnavutluğun işgali ile ilgili olumsuz şeyler söylemez. Hatta karşı çıkanları eleştirir gibidir. Roncalli, Lettersto His Family, 352. Daha önce Mussolini ile ilgili söylediklerine tezat bazı cümleleri de göze çarpar bu dönemde yazdığı mektuplarda. Örneğin onun daha iyi bir İtalya için çalıştığını, ona müteşekkir olunması gerektiğini ifade eder. Bkz. Roncalli, Lettersto His Family, 367.

48 Roncalli, Lettersto His Family, 348.

49 Lettersto His Family, 349.

50 Hebblethwaite, ., 158.

51 Bkz. Giorgio Conetti, "Monsignor Roncalli, later Pope John XXIII and Turkish neutrality in the first period of the Second World War (September 1939-June 1941)", Milletlerarası Münasebetler Türk Ylllı̆̆l / The Turkish Yearbook of International Relations, vol. IX, 1968, 64-74.

52 Von Papen'le ilgili bkz. Roncalli, Oriente I, 709, 712; Roncalli, Oriente II, 5, 6, 105, 233, 375, 448, 582, 707, 775. Franz Von Papen'in biyografisi için bkz. Richard W. Rolfs, The Sorcerer's Apprentice: The life of Franz vonPapen (UniversityPress of America: Maryland, 1996). Roncalli Von Papen ilişkisi hakkında bkz. Stefano Trinchese, Roncalli e von Papen: rapporti diplomatici e strategie d'impegno comune di due protagonisti del XX secolo (Societá Editrice Internazionale: Torino, 1996).

53 Mussolini’nin dışişleri bakanının günlüklerinden aktaran Hebblethwaite, 166. 
Hitler'in Yunanistan'ı işgali Nisan 1941'de başlamış ve Ekim 1944'te Almanların bu bölgeden çekilmesi ile son bulmuştur. Aslında Yunanistan'ı ilk olarak işgal etmeye kalkışan devlet İtalya'dır. Ekim 1940'ta bu ülkeye saldıran İtalya'nın yaşadığı başarısızlığın ardından Hitler, Balkanlar'ı kontrol altına alabilmek için ordusunu Yunanistan'a yönlendirir. 1941 Nisan'ında Almanların Yunanistan'a girmesinin ardından Yunanistan Mayıs ayında artık Almanya, İtalya ve Bulgaristan olmak üzere üç farklı devletin işgali altındadır. İşgal süresince halk birçok zorluk ile karşı karşıya kalır ve 300.000 sivil açlık ve salgın hastalıklardan dolayı yaşamını yitirir. Ülke ekonomisi tamamen çökmüştür. 1943 yılına gelindiğinde direnişçi gruplar birbirleriyle çatışmalara girmişler ve tam bağımsızlığın alındığı 1944 yılında dahi krizde olan ülkede iç savaşın çıkmasına neden olmuşlardır. ${ }^{54}$

İtalya'nın savaşa dahil olması Roncalli'yi üzdüğü gibi son derece zor bir durumda bırakmıştır. Yunanistan'da bir İtalyan, yani işgalcilerden biridir artık. Sadece Türkiye'nin tarafsızlığı onu bir ölçüde rahatlatmaktadır. Fakat burada da birbiriyle savaşan devletlerin diplomatlarıyla ilişkileri hassas bir hal almıștır. ${ }^{55}$ Yunanistan'a gideceği zamanlarda Von Papen'den bir izin belgesi almak zorundadır. Gerek Hitler gerekse Mussolini savaş şartları dolayısıyla Kiliseye daha sıcak mesajlar vermektedir. Vatikan'ın bu dönemdeki siyasetinde etkili olan önemli isimlerden biri ise ileride Roncalli ile yolları Roma'da kesişecek olan, Devlet Sekreterliği'nin dış ilişkiler sorumlusu Domenico Tardini'dir. Roncalli'nin mutad görevi olan Vatikan'a rapor bildirme işinin önemi savaș döneminde daha da artmıștır. Fakat onun olabildiğince tarafsız ve yorum katmadan kaleme aldığı iyimser raporları Tardini tarafından kendisinin "fazla saf" olduğu ve "hiçbir şeyi anlamadığı" yorumları yapmasına neden olur. ${ }^{56}$ Roncalli bir ara Sofya'ya gider ve buradaki halefi Mazzoli ile görüşür. Ardından Kal Boris ve Kraliçe Giovanna ve Metropolit Stefan'ı ziyaret eder. ${ }^{57}$ Kral Boris Roncalli'ye Rusya'nın kendisini Türkiye'ye saldırmaya zorladığını anlatır. En azından savaş döneminde Katolik Kilisesi ile Bulgaristan arasındaki ilișkiler Roncalli'nin Sofya günlerine nispetle daha iyi olmuştur. Yunanistan'da ise Alman ve İtalyan kuvvetlerinin komutanlarıyla görüşmeleri olmuştur Roncalli'nin. Hatta Yunanistan'daki İtalyan birlikleri arasında memleketinden, Bergamo'dan askerler de vardır. ${ }^{58}$

Roncalli insani yardım konusunda son derece hassastır. Kendi özel hayatında da fakirlere yardım etmeyi görev bilir. Günlüklerinden "Sotto il Monte'deki fakirler için", “Carvico'daki fakirler için...” şeklinde planlamalar yaptığı ve kendi bütçesinden oradaki insanlara yardım gönderdiği anlaşılmaktadır. ${ }^{59}$ Savaş zamanında Yunanistan'daki açlık ve sefalet için de çok çaba sarfeder. Fakat bu çabalar çoğunlukla Vatikan bürokrasisi veya savaş siyaseti arasında kaybolur. Ayrıca bir din adamı olarak savaşın kötülüguünü anlatmak ve barış için dua etmek gibi bir misyon görmüștür kendisinde. Savaş ve kötülüklerini anlatırken şöyle yazar ruhsal günlüğüne: "Kötülük mü? Hangi kötülük? Kötülük biziz. Olan kötülüklerden

54 Bkz. P. Hoffmann, "Roncalli in the Second World War: PeaceInitiatives, The Grek famine and the Persecution of theJews", Journal of EcclesiasticalHistory, XL (1989), 74-99. Roncalli'nin Yunanistan'da savaş mağduru açlık çeken çocuklara yardım çabası için bkz. Marmara, 92-96.

55 Bazları Roncalli'nin yabancı misyon şefleriyle iletişimini "ne çok uzak ne çok yakın" şeklinde bir siyasetle yürütmeye çalıştığını ifade eder. Hebblethwaite, 175.

56 Bkz. Hebblethwaite, s. 169.

57 Roncalli, Oriente II, 249, 251.

58 Bkz. Roncalli, Lettersto His Family, 409.

59 Bkz. Roncalli, Oriente II, 690. 
biz sorumluyuz". ${ }^{60}$ Roncalli'nin savaş dönemindeki bu tecrübelerinin II. Vatikan Konsili metinlerinden Lumen Gentium'a önemli bir etkisi olduğunu düşünülür. ${ }^{61}$ İstanbul'da barış için düzenlediği bir etkinliği Cumhuriyet gazetesi o dönem şöyle haber yapmıştır:

“Dün sabah saat 10 da Harbiyede Saint-Esprit kilisesinde; Papanın Türkiye mümessili Monsinyor Roncalli'nin riyasetinde bir sulh duası yapılmıştır. Bu âyini ruhaniye Ermeni katolikleri başpapazı Kireçyan, Rum katolikleri reisi ruhanisi Varuhas, Rumen, Macar, İtalyan, Alman konsolosları ile şehrimizdeki katoliklerden büyük bir grup iştirak etmişlerdir. Monsinyor Roncalli bir nutuk söylemiş ve merasimi Ermeni cemaati reîsi Kireçyan idare etmiştir. Şehrimîz kiliselerinden seçilmiş bir koro heyeti tarafından şarkılar okunmuştur. Merasim öğleden sonra 16,30 da tekrar edilmiş ve gece de Papanın Vatikan radyosunda okuduğu mesaj dinlenmiştir. Bu merasim şehrimizin bütün Katolik kiliselerinde de yapılmıştır."62

1943 yılına gelindiğinde Hitler ve müttefikleri artık gerileme halindedir. Nazilere karşı savaşın en önemli gücü Amerika olacaktır. Roncalli 11 Mayıs 1943'te Roma'dan, Kardinal Maglione'den bir telgraf alır. Maglione New York Başpiskoposu Kardinal Francis Spellman'ın ziyaretini haber vermektedir. ${ }^{63}$ Spellman 14 Mayıs'ta Haydar Paşa garına iner. Roncalli Spelmann'la görüşmesinden oldukça memnun olduğunu yazar günlüğüne. ${ }^{64}$ Fakat bu ikilinin yıldızı ileride pek barışmayacaktır. Amerikalı kardinalin ziyareti sadece dinî değildir. Spellman'ın görüştügü isimler arasında Cumhurbaşkanı İsmet İnönü de vardır. İnönü Spellman'ı 17 Mayıs 1943'te Ankara'da kabul eder. ${ }^{65}$ Kardinal üst düzey bir protokolle ağırlanır. Roncalli biyograflarından biri "Spellman başpiskopos olduğu için değil, Amerikalı olduğu için bu şekilde onurlandırıldı" diye yazar. ${ }^{66}$

Temmuz ayına gelindiğinde müttefikler Sicilya'ya asker çıkarır. İtalya'da Mussolini yolun sonuna gelmiştir. Kısa bir süre sonra tutuklanır. Kral Victor Emmanuel ise İsviçre’ye kaçar. Artık İtalya'da yönetim Sosyalistler, Liberaller ve Hıristiyan Demokratlar'ın hepsinin bir araya geldiği Milli Bağımsızlık Komitesi'ndedir. İtalya 13 Ekim 1943’te Almanya'ya savaş ilan eder. İtalya'daki yeni hükümetin dıșișleri bakanı Roncalli'nin tanıdığı bir isim, İtalya'nın Ankara büyükelçiliğini yapmış olan RaffaeleGuariglia'dır. Roncalli 1944 Ağustosunda Roma'da bakanla görüşme imkanı bulur ve mektuplarında yazdığına göre onun hükümette olması kendisine güven vermektedir. ${ }^{67}$ Sovyetler Birliği ve Polonya kuvvetlerinin Berlin'i ele geçirmesini müteakip, Almanya'nın 8 Mayıs 1945'de koşulsuz teslimiyetiyle birlikte

60 Roncalli, IlGiornale, 355.

61 Bkz. Hebblethwaite, 171.

62 Cumhuriyet, "Sulh için dua", İkinciteşrin, 1943, s. 1. Roncalli'nin İstanbul'daki vaazları ve diğer konuşmaları için ayrıca bkz. A. G. Roncalli (Giovanni XXIII), La predicazione a İstanbul: Omelie, discorsi e note pastorali (1935-1944)(Olschki, Leo S. (ed.), Biblioteca della Rivista di Storia e Letteratura Religiosa, testi e documenti, vol. XV: Firenze, 1993).

63 Roncalli, Oriente II, 559. Kardinal Spellman zaman zaman "Amerika'nın Papası" şeklinde isimlendirilen ABD'de o dönem en etkili Katolik din adamıdır. Sonraki yıllarda, ABD’nin tek Katolik başkanı olacak olan Kennedy ile de yakın bir ilişkisi mevcuttur. Kardinal Spellman'ın ayrıntılı bir biyografisi için bkz. John Cooney, The American Pope: The Life and Times of Francis Cardinal Spellman (Times Books: New York, 1984).

64 Roncalli, Oriente II, 561.

65 Roncalli, Oriente II, 571.

66 Roncalli, Hebblethwaite, 189.

67 Roncalli, Lettersto His Family, 471. 
Avrupa'da savaş sona erer. Roncalli ise savaş sona ermeden başka bir göreve atanır. 6 Aralık 1944'te Tardini'den aldığı bir telgrafla, Fransa'ya Papalık elçisi olarak atandığını öğrenir. Bu, onun için tam bir sürprizdir. ${ }^{68}$ Charles de GaulleFransası yeni görev yeridir.

\section{Diplomatik Faaliyetleri}

Roncalli'nin savaş yıllarındaki en önemli icraatlarından biri de soykırımdan kaçan Yahudilere yaptığı yardımlardır. ${ }^{69}$ Öyle ki, Reisman “Türkiye'nin geçiş izni vermesiyle kurtulan Yahudilerin öyküsü, Monsenyör Angelo Roncalli'den söz etmeden geçiştirilemez"70 der. İlk olarak Polonya'dan kaçan Yahudilere Filistin'e gidebilmeleri için yardım etmiştir. Bunlar arasında Slovakya'dan gelenler de vardır. ${ }^{71}$ Savaşta tarafsız olan Türkiye'nin soykırımdan kaçan Yahudilere açıkça yardımcı olması tarafsızlığa gölge düşürecektir. Dolayısıyla Roncalli'nin ancak Türk yetkililerin desteğiyle bu yardımları gerçekleştirebildiği söylenebilir. Kaldı ki Menemencioğlu gibi önemli hariciyeciler sadece Roncalli aracılığıyla değil başka temaslar neticesinde de pek çok yahudinin hayatını kurtarmıştır. ${ }^{72}$ Roncalli özellikle 1943 yılında o dönem aktif bir şekilde çalışan Yahudi Ajansı'nın İstanbul'daki sorumlusu Haim Barlas'la işbirliği yapar. ${ }^{73}$ Barlas Roncalli'ye Vatikan'ın, radyosunu da kullanarak Yahudiler konusunda daha açık bir tepki göstermesi konusunda Curia'yı teşvik etmeye ikna ettiyse de Vatikan yönetimi buna hiç sıcak bakmamıștır. ${ }^{74}$ Roncalli'nin bu konuda ayrıca Yahudi Ajansı'nın finans işleri sorumlusu Eliezer Kaplan ve zamanın Yahudi Hahambașı Markus ile de görüşmeleri olmuştur. ${ }^{75}$ Şubat 1944'te ise Kudüs Başhahamı İsaac Herzog'la görüşür. Konu Romanyalı 55.000 yahudinin kaderidir. Yine aynı yıl Amerika'da Başkan Roosevelt tarafindan kurulan Savaş Mültecileri Kurulu (WarRefugee Board)'nun İstanbul'daki görevlisi Ira Hirshman ile bir görüşme yapar. Konu yine savaştan kaçan Yahudilerdir. ${ }^{76}$ Roncalli, Vatikan'ın Romanya ve Macaristan'daki diplomatlarıyla ilişki kurup Yahudi Ajansı'nın verdiği Mülteci Sertifikası almalarını sağlamış ve bunların Filistin'e geçmelerine yardımcı olmuştur. Hatta bu sertifikaya ek olarak kendisinin sahte vaftiz belgeleri düzenlediği filmlere de konu olmuş bir efsanedir. ${ }^{77}$

68 Roncalli, Lettere, 287. Yeni görevine atanması ve Türkiye'den ayrılma süreci ile ilgili bkz. Melloni, FraIstanbul, 301-306.

69 Melloni, FraIstanbul, 287-291.

70 Arnold Reisman, Nazizmden Kaçanlar ve Atatürk'ün Vizyonu, çev. Gül Çağalı Güven (Türkiye İş Bankası Yayınlar1: İstanbul, 2011), 463.

71 Hebblethwaite, 186-188.

72 Bkz. Reisman, 404, 405. Türkiye'nin soykırımdan kaçan Yahudilere yardımları konusunda ayrıntılı bir çalışma için bkz. S.J. Shaw, Turkey and the Holocost: Turkey's Role in Rescuing Turkish and European Jewry from Nazi Persecution, 1933-1945 (New York: 1994), 274-297; Dina Porat, The Blue and the Yellow Stars of David: The Zionist Leadership in Palestine and the Holocaust, 1939-1945 (Harvard University Press: Massachusetts, 1990).

73 Yahudi Ajansı'nın temel görevi “aliya” (“İsrail'e göç”) organizasyonudur ve İsrail hükümetinden 2007’ye kadar fon alan tek kuruluştur. Roncalli’nin Barlas'la görüşmeleri hakkında bkz. Roncalli, Oriente II, 546, 564, 566, 691, 692; Barlas ve faaliyetleri hakkında bkz. Reisman, 346, 460-463, 597. Roncalli-Barlas ilişkisi hakkında ayrica bkz. Dina Porat, "Tears, Protocols and Actions in a Wartime Triangle: Pius XII, Roncalliand Barlas", Cristianesimo nella storia, XXVII/2, maggio 2006, 599-632.

74 Roncalli, Oriente II, 743.

75 Bkz. Roncalli, Oriente II, 534, 557, 748.

76 Roncalli,Oriente II, 755, 756. Hirshman sonraki yıllarda günlüklerinde Roncalli ile ilgili izlenimlerini yazmış ve Yahudilere yardım konusunda ondan övgüyle söz etmiştir. Hirshman'ın günlüklerinden bu konudaki aktarımlar için bkz. Shaw, 297, 298.

77 Hebblethwaite, 195. 
Savaş zamanında Yahudilere yardım eden Roncalli savaş sonrasında İsrail Devleti'nin kurulmasını da desteklemiş midir? Bu konuda açık bir desteğine rastlanmaz. Hatta böyle bir fikre soğuk baktığı bile söylenebilir. Zira bazı meslektaşlarının endişe ve şüphelerine katılarak, 4 Eylül 1943'te Devlet Sekreterliği'ne yazdığı mektupta savaştan kaçanların Filistin'de toplanmasının, burada bir Yahudi devleti kuracağına dair şüphe uyandırdığını ifade etmiştir. ${ }^{78}$ Bununla birlikte 0 , savaştan kaçan Yahudilere gerçekten bütün samimiyetiyle yardım etmiştir. Bu konuda yardımını gördüğü isimlerden biri de Alman Büyükelçi Von Papen'dir. Fakat 2 Ağustos 1944'te Türkiye Almanya ile diplomatik ilişkisini keser, VonPapen ve ailesi Türkiye'den ayrılmak zorunda kalır. VonPapen, Yahudileri kurtarma konusunda Roncalli'ye olan desteğinin karşılığını daha sonra görecektir. Roncalli'nin Fransa'da Papalık elçisi olarak görev yaptığı sırada Nürnberg'teki Uluslararası Savaş Suçları Mahkemesi'ne yazdığı bir mektup Von Papen'in hayatını kurtaracaktır.

\section{Türk Bürokratları ve Siyasetçileriyle İlişkileri}

Roncalli Türkiye'ye gelişinden itibaren doğal olarak bazı siyasetçi ve bürokratlarla iletișim içerisinde olmuştur. Hatta bunlar arasında bazıları ile özel bir dostluk kurmuştur. Bu isimlerden en önemlisi herhalde Numan Menemencioğlu'dur. Tanıșmaları 1937 yılının Ocak ayındadır. ${ }^{79} \mathrm{Bu}$ ikili daha sonra Fransa'da da birlikte çalışacaktır. Menemencioğlu hayatını yazsaydı muhtemelen Roncalli ile ilgili önemli bilgiler verecekti. Ama ondan yapılan bazı aktarmalar, Roncalli'nin bazı hususlardaki tavrı ile alakalı bize ipuçları vermektedir. Örneğin Menemencioğlu Roncalli ile birlikte Adnan Saygun'un bestelediği Yunus Emre Oratoriosu'nu dinler. Eserden çok etkilenen ve heyecanlanan Roncalli konser çıkışında Menemencioğlu'na şöyle der: "ne tuhaf. İçten geldiği zaman bütün sanat eserleri Tanrı’yı aynı dille övüyorlar. Bu eserin güzelliğini bir Müslüman kadar bir Katolik de neden anlamasın?"80

Roncalli Türkiye'den ve Türklerden her zaman saygı ve övgüyle bahsetmiştir.81 "Türkleri seviyorum" onun İstanbul dönemi ile alakalı en çok atıfta bulunulan cümlesidir. ${ }^{82}$ Türkiye`de Roncalli'ye yönelik ilgide onun bu tavrının şüphesiz önemli bir etkisivardır.Vatikan'la Türkiye arasında diplomatik ilişki kurulmasında da Roncalli'nin oluşturduğu bu yakınlık etkili olmuştur. Türkiye henüz Vatikan'ı resmen tanımıyorken, 1955'te Başbakan Adnan Menderes Papa XII. Pius'u ziyaret eder. 1958'de Pius'un yerine Roncalli papa seçildiğinde ise dönemin dış işleri bakanı Fatin Rüştü Zorlu bir Türk dostunu papalık makamında görmenin mutluluk verici olduğunu açıklar. Ertesi yıl Cumhurbaşkanı Celal Bayar Roncalli'yi makamında ziyaret eder. ${ }^{83}$ Bu gelişmelerin ardından 1960'ta

78 Nakleden Hebblethwaite, 192.

79 Bkz. Roncalli,Oriente I, 282. Numan Rifat Menemencioğlu (1893-1958) 1942'den 1944'e kadar Şükrü Saraçoğlu hükümetlerinde Dışişleri Bakanlığı yapmıştır. 30 Kasım 1944 tarihinde Paris Büyükelçiliğine atanmıştır. 1956 yılında bu görevden emekli olmuş; İstanbul milletvekili seçilmiş; 15 Şubat 1958'de ölmüştür. Roncalli'nin İstanbul günlüklerinde Menemencioğlu ile ilgili kısımlar için bkz. Roncalli, Oriente I, 284, 430, 434, 515, 669; Roncalli, Oriente II, 377, 440.

80 “İki Papa", Cumhuriyet, 2 Aralık, 1958, s. 3. Roncalli Paris’te de Yunus Emre ile ilgili bir programa katılmış ve aynı beğenisini ifade etmiştir. Bkz. Roncalli, AnnidiFrancia I, 306.

81 Bkz. Roncalli, Journal, 252.

82 Roncalli, Journal, 233; Roncalli, IlGiornale, 344. Roncalli’nin Türkiye izlenimleri ve Türklerle ilgili hissiyatı için bkz. VittoreUgoRighi, Papa Giovanni XXIII sullerive del Bosforo (Edizioni, Messaggero: Padova, 1971), 121-133; Marmara, 67-78; Melloni, 56-75.

83 Altındal Roncalli ile Bayar'ın, Roncalli’nin İstanbul günlerinden itibaren iyi dost olduklarını belirtir. 
Vatikan'la Türkiye arasında resmen diplomatik ilişki kurulur. FrancescoLardone Vatikan'ın ilk Türkiye elçisi, Nureddin Vergin de Türkiye'nin ilk Vatikan Büyükelçisi olur. 27 Mayıs darbesi sonrasındaki sıkıyönetim döneminde de Türkiye'deki Roncalli sempatisi devam eder. 1960'da Katolik cemaati tarafından, Roncalli'nin İstanbul'da iken ikamet ettiği Ölçek Sokak'taki binaya onun anısına bir plaket yerleştirilmesi kararlaştırılmıştır. Ancak sıkıyönetim nedeniyle her türlü toplantı ve tören yasaklandığından Lardone o zaman İstanbul Valisi olan General Refik Tulga'dan törenle ilgili izin istemeye gittiğinde Tulga sadece izin vermekle kalmaz, törene bizzat katılıp açılışı yapar ve Roncalli'nin“tarihteki ilk Türk papa” olduğunu söyler. 1963 yılında ölmeden önce Roncalli'yi bir Türk yetkilisi daha ziyaret eder. Bu kişi dönemin dış işleri bakanı Feridun Cemal Erkin'dir. ${ }^{84}$

Yakın geçmişe bakıldığında Roncalli'nin Türkiye'de -en azından yönetim tabakasıncasempati ile bakılan ilk ve tek papa olduğu görülür. ${ }^{85}$ 1986'da 10-17 Kasım tarihleri arası Roncalli'nin İstanbul'a gelişinin 50. yılı münasebetiyle Roncalli Haftası ilan edilmiş; bu hafta dolayısıyla yapılan bir törendeki konuşmasında eski dış işleri bakanlarından İhsan Sabri Çağlayangil Roncalli'den "Türk dostu papa” olarak söz etmiştir. Roncalli'nin Aziz ilan edildiği 2000 yılı Aralık ayında ise -aziz ilan edildiği törene dönemin kültür bakanı İstemihan Talay ve diğer bazı devlet erkanı da katılmıştır- Roncalli'nin oturduğu, bugün Papalık Büyükelçiliği olarak hizmet veren binanın yer aldığı Ölçek Sokak'ın adı Mustafa Sarıgül başkanlığındaki Şişli Belediye Meclisinin aldığı kararla "Papa Roncalli Sokağı" olarak değiştirilmiştir. Kültür Bakanlığı tarafından 8-10 Aralık 2000 tarihleri arasında Roncalli onuruna düzenlenen kutlamalar çerçevesinde -kutlama komitesinin başkanı eski bakanlardan İmren Aykut'turçeşitli siyasî ve dinî liderlerin katılımıyla gerçekleştirilen bir törenle yeni sokak tabelası yerine konur. $^{86}$

Roncalli, bir dönem dışişleri bakanlığı yapmış olan Menemencioğlu yanında o dönem ve sonrasında Türkiye'de etkili olan pek çok isimle de teşrik-i mesaide bulunmuştur. Bunlar arasında yine Türkiye'de bulunduğu süre içinde dışişleri bakanlığı yapmış olan Tevfik Rüştü Aras $^{87}$ ve Şükrü Saraçoğlu ${ }^{88}$; o dönem hariciyesinin önemli isimlerinden Nebil Batı ${ }^{89}$; Papa olduktan sonra Türkiye Cumhurbașkanı olarak kendisini ziyaret edecek olan Celal Bayar ${ }^{90}$; Atatürk döneminin değişmez İçişleri Bakanı Şükrü Kaya ${ }^{91}$; "çok kibar ve bilgili bir insan"

Hatta,Roncalli’yi “Celal Bayar’1 ipten alan papa” olarak isimlendiren Altındal'a göre 27 Mayıs darbesi sonrasında Menderes ve arkadaşlarıyla beraber idama mahkum edilen Bayar'ın idam edilmemesinin arkasında Roncalli'nin müdahalesi vardır (bkz. Aytunç Altındal, 83, 84). Fakat hiçbir belgeye dayanmayan bu iddia tamamen bir spekülasyondan ibarettir.

84 Bkz. Rinaldo Marmara, "Papa 23. John Aziz İlan Ediliyor”, çev. S. Öztürk, Toplumsal Tarih, S. 80 (Ağustos 2000), 50-54.

85 Ülkemizde Papalığı bir düşman veya tehlike olarak anlatan bazı kitaplarda dahi XXIII. John bir istisna olarak ayrı bir yere yerleştirilir. Bkz. Münir Abdurrahman, Papaların Tarih Boyunca İslam-Türk Düşmanlığl (İstanbul, 1967), 73, 74. Bununla birlikte son dönemde Aytunç Altındal gibi “Türk Papa” anlayışının bir kandırmaca olduğunu iddia edenler de vardır. Bkz. Aytunç Altındal, Vatikan ve Tapınak Şövalyeleri (Ankara, 2002), 81 vd.

86 Bkz. Rinaldo Marmara, "Papa Roncalli: Ölçek Sokak’ın Yeni Adı”, çev. S. Özen, Toplumsal Tarih, S. 85 (Ocak 2001), 57-59.

87 Roncalli, Oriente I, 226, 336, 515.

88 Roncalli, Oriente II, 377, 440.

89 Roncalli, Oriente I, 434, 515.

90 Roncalli, Oriente I, 515.

91 Roncalli, Oriente I, 226. 282. Algisi Şükrü Kaya'nın mason olduğunu, kızının da İstanbul'daki 
diye bahsettiği, arkeolog ve siyasetçi Remzi Oğuz Arık²; "Türk ama ateşli bir Katolik" olarak andığı Dr. Murat Rami Aydın; ${ }^{93}$ o dönemin Hukuk Gazetesi'nin yöneticisi Cevat Hakkı Özbey ${ }^{94}$; "Mustafa Kemal'i Türk basınına tanıtan adam" olarak bilinen ve daha sonra da Atatürk'ün çalışma arkadaşlarından biri olmuş Ruşen Eşref Ünaydın; ${ }^{95}$ Atatürk'ün doktoru Neșet Ömer ${ }^{96}$; Lozan görüşmeleri dahiluzun dönem yurtdışında Türkiye ile ilgili pek çok kurum ve toplantıda yer almış Reşid Saffet Atabinen ${ }^{97}$ bunlardan bazılarıdır. ${ }^{98}$

\section{Sonuç}

Angelo GiuseppeRoncalli Katolik Kilisesinde belli bir kariyer düzeyine gelmesinin ardından -bazılarına göre Roma'da uzak tutulmak için-önce Bulgaristan sonra da hem Türkiye hem de Yunanistan papalık elçiliği göreviyle İstanbul'a gönderilmiştir. İstanbul'da geçirdiği yaklaşık on yıllık dönem şüphesiz onun tecrübe dünyasına önemli katkılar sağlamıştır. 1935-1944 yılları arasını kapsayan bu dönem hem Türkiye hem de tüm dünya için zorlu bir devredir. Bununla birlikte o, din adamından ziyade bir diplomat gibi çalışmış ve iyi insani ilişkileri sayesinde başarılı bir görev dönemi geçirmiştir.

Türkiye'deki Katolik kiliselerinde ayinde ilk defa Türkçe kullanılmaya başlanması onun dönemindedir. Yine Numan Menemencioğlu başta olmak üzere önemli Türk bürokratları ve siyasetçileriyle iyi ilişkiler kurması, papalığı döneminde Türkiye ile Vatikan'ın diplomatik ilişki kurmasının temelini oluşturmuştur denebilir. Diğer yandan, Avrupa'dan kaçan Yahudilere yardımcı olması onu Yahudilerce de istisna bir kişi olarak görülmesini sağlamıştır.

Türkiye'deki görevi esnasında sadece İstanbul'da kalmamış birçok Anadolu şehrini, hatta Ortadoğunun muhtelif yerlerini ziyaret etmiş ve farklı kültür ve inançtan birçok çevre ile temasta bulunmuştur. Onun bu Doğu tecrübesinin papalık dönemine de yansıdığı; ibadet dilinde serbestlik ve diğer dinlerle ilişkiler başta olmak üzere II. Vatikan Konsili'nin getirdiği birçok değişimde bu tecrübenin önemli bir etkisi bulunduğunu iddia etmek abartı olmaz.

SiyonKızkardeşleri (SorediSion)'nde okuduğunu söyler. Ayrıca Kaya’nın zamanın İtalya Büyükelçisi Galli’ye şöyle dediğini nakleder: "İslam dinini etkisizleştirip Hıristiyanlığın önünü açtığımız için siz Katolikler bize minnettar olmalısınız." Algisi, John thetwenty-third, 109.

92 Roncalli, Oriente I, 189.

93 Roncalli, Oriente I, s. 37. 286, 516, 664.

94 Roncalli, Oriente I, 218, 535.

95 Günlüklerde “Aydın” şeklinde geçmektedir. Bkz. Roncalli, Oriente II, 608, 634.

96 Roncalli, Neşet Ömer (günlüklerde Necit Ömer veya Nechet Ömer şeklinde geçmektedir) ile 6 haziran 1941 'de tanışmış ve bu tarihten sonra pek çok defa kendisiyle görüşmüştür. Bkz. Roncalli, Orinte II, 238, 575, $760,763$.

97 Atabinen, Roncalli’nin antik eserlerin restorasyonu ile ilgili bir komisyonun başındaki isim olarak tanıdığı ve Katolik eserlerinin restorasyonu konusunda birçok defa görüştüğü, birlikte yemekler yediği bir kişidir. Bkz. Roncalli, Oriente II, 699, 701, 799.

98 Günlüklerde sık geçen başka isimler de vardır. Bunlardan Dilek Ural hukuki işlerde Roncalli’ye yardımcı olan ve kilise emlakı ile ilgili davalara bakan avukattır. İstanbul barosu kayıtlarına göre 1956 yılında ölmüştür. Roncalli’nin, tahsiline yardımcı olduğu bir öğrenci olarak söz ettiği Cemil Aras ise Mardinli bir süryanidir. Çok partili hayata geçilmesinin ardından Belediye Meclis Üyesi olmuştur. Bkz. Roncalli, Oriente II, 724. 


\section{KAYNAKÇA}

Alberigo, Angelina Guiseppe, Giovanni XXIII, Profezianellafedeltá(EditriceQueriniana:Brescia, 1978).

Algisi, Leone, John thetwenty-third, trans. by Peter Ryde(NewmannPress:London, 1966).

Altındal, Aytunç, Vatikan ve Tapınak Şövalyeleri(Yeni Avrasya Yayınları: Ankara, 2002).

Capovilla, Loris F.,XVanniversariodellamortedi papa Giovanni, 1963 -3 giugno1978(EdizionidiStoria e Letteratura: Roma, 1978).

Capovilla, Loris F.,TheHeartandMind ofJohn XXIII, trans. byPatrickRiley, (HawthornBooks: New York, 1964).

Conetti, Giorgio, "MonsignorRoncalli, laterPope John XXIII andTurkishneutrality in thefirstperiod of the Second World War (September 1939-June 1941)", MilletlerarasI Münasebetler Türk Yıllığı / TheTurkish Yearbook of International Relations, vol. IX, 1968, 6474.

DellaRocca, RobertoMorozzo, "Roncallidiplomatico in turchia e greca", Christianesimonellastoria, VIII/2, giugnio 1987, 33-72.

Giovanni XXIII, Lettereaifamiliari 1901-1962(a cura diLorisFrancescoCapovilla, vol. I-II, EdizionidiStoria e Letteratura: Roma, 1968).

Hoffmann, P., "Roncalli in the Second World War: PeaceInitiatives, The Grek famineandthePersecution of theJews", Journal of EcclesiasticalHistory, XL (1989), 74-99.

Küng, Hans, TheChurch(Image Books: New York, 1976).

Marmara, Rinaldo, "Papa 23. John Aziz İlan Ediliyor", çev. S. Öztürk, Toplumsal Tarih, S. 80 (Ağustos 2000), 50-54.

Marmara, Rinaldo, "Papa Roncalli: Ölçek Sokak'ın Yeni Adı”, çev. S. Özen, Toplumsal Tarih, S. 85 (Ocak 2001), 57-59.

Marmara, Rinaldo, Türk Dostu Papa XIII. Jean, çev. Dominik Pamir, (İstanbul, 2000).

Melloni,Alberto,FraIstanbul,Ateneelaguerra(1935-1944)(CasaEditriceMarietti:Genova, 1992).

Pope John XXIII, Journal of a Soul: TheAutobiography of Pope John XXIII, trans. byDorothy White (Image BooksDoubleday: New York, 1980).

PopeJohnXXIII,LetterstoHisFamily,trans. byDorothyWhite(McGraw-HillBookCompany: New York, 1970). 
Porat, Dina, "Tears, ProtocolsandActions in a WartimeTriangle: Pius XII, Roncalliand Barlas", Cristianesimonellastoria, XXVII/2, maggio 2006, 599-632.

Porat, Dina, The Blue andtheYellow Stars of David: TheZionistLeadership in PalestineandtheHolocaust, 1939-1945(Harvard UniversityPress: Massachusetts, 1990).

Reisman, Arnold, Nazizmden Kaçanlar ve Atatürk'ün Vizyonu, çev. Gül Çağalı Güven (Türkiye İş Bankası Yayınları: İstanbul, 2011). 1971).

Righi, VittoreUgo, Papa Giovanni XXIII, sullerive del Bosforo(Edizioni, Messaggero:Padova,

Roncalli, A. G. (Giovanni XXIII), La predicazione a İstanbul: Omelie, discorsi e note pastorali (1935-1944)(Olschki, Leo S. (ed.), BibliotecadellaRivistadiStoria e LetteraturaReligiosa, testi e documenti, vol. XV:Firenze, 1993).

Roncalli, Angelo Giuseppe, Giovanni XXIII, AnnidiFrancia, Agende del Nunzio 1: 1945-1948(Edizionecritica e annotazione a cura diÉtienneFouilloux, Istitutoper le ScienzeReligiosedi Bologna: Bologna, 2004).

Roncalli, Angelo Giuseppe, Giovanni XXIII, IlGiornaledell'anima, Soliloqui, note e dairi spirituali(Edizionecritica e annotazione a cura diAlbertoMelloni, Istitutoper le ScienzeReligiosedi Bologna: Bologna, 2003).

Roncalli, Angelo Giuseppe, Giovanni XXIII, La miavita in Oriente, Agende del delegatoapostolico 1: 1935-1939(Edizionecritica e annotazione a cura diValeriaMartano, Istitutoper le ScienzeReligiosedi Bologna: Bologna, 2006).

Roncalli, Angelo Giuseppe, Giovanni XXIII, La miavita in Oriente, Agende del delegatoapostolico 2: 1940-1944(Edizionecritica e annotazione a cura diValeriaMartano, Istitutoper le ScienzeReligiosedi Bologna: Bologna, 2008).

Roncalli, Angelo Giuseppe, Giovanni XXIII, Tener da conto, AgendediBulgaira 1925-1934(Edizionecritica e annotazione a cura diMassimoFaggioli, Istitutoper le ScienzeReligiosedi Bologna: Bologna, 2008).

Shaw,S.J.,TurkeyandtheHolocost: Turkey's Rolein Rescuing TurkishandEuropeanJewryfrom Nazi Persecution, 1933-1945(New York: 1994).

Trevor, Meriol, Pope John, Blessed John XXIII(MPG Boks:London, 2000).

Trinchese, Stefano, "Roncallidiplomatico in Grecia e in Turchia", Pio XII, EditoriLaterza, Bari, 1984, 231-264

Trinchese, Stefano, Roncalli e vonPapen: rapportidiplomatici $e$ strategied'impegnocomunedidueprotagonisti del XX secolo(SocietáEditriceInternazionale: Torino, 1996). 